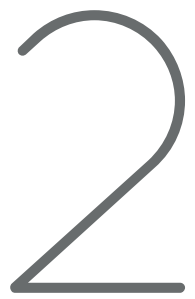

\title{
NO SERA AUDAZ NI TEMERARIO
}

\author{
Simón Espinosa Cordero
}

I S Universidad Verdad, Núm. 1

Enero - Abril 1986, ISSN: 1390-28489 universidad 21 ช

verdad

UNIVERSIDAD 


\section{Al fin de la batalla}

y muerto el individuo, vino hacia él un hombre y le dijo:

y le dijo: ";No mueras, te amo tanto!"

Pero el cadáver jay! siguió muriendo.

No será audaz aplicar estos versos de César Vallejo al cadáver de Hernán Malo González. No había él leído nunca a Vallejo, rezagos de la formación europeizante de la Compañía de Jesús que, en los años de formación de sus jóvenes, soslayaba sistemáticamente todo lo latinoamericano y ecuatoriano. Pero un domingo de sol leí a Hernán Malo unos poemas de Vallejo. Desde entonces venía con frecuencia a casa para leer a Vallejo y limpiar así "el esqueleto".

No será temerario preguntarse por qué la gente que conocía a Malo, al saber de su muerte, se dijo de diversas maneras: " ¡No mueras, te amo tanto!". Una no inverosímil respuesta podría ser: porque en él se cumplió clara y distintamente la teoría platónica de la división tripartita de la naturaleza del alma: la parte racional (to logisticon), la parte valerosa (to zimoides), la parte apetitiva (to epizimeticon). La razón es un claro en el bosque de la confusión humana. Invita al sosiego, permite orientarse, deja entrar la luz. La gran tesis de Hernán Malo fue definir la universidad como sede de la razón y vivir la docencia, el rectorado y el quehacer intelectual por ella, desde ella y para ella. El amor a la razón lo llevó a un corolario: ecuatorianizar la universidad, le condujo al diálogo con la universidad laica, hasta entonces tabú en la Católica, sellada por un nada histórico confesionalismo de corte infalible y pantalón corto. El amor a la razón le impelió a conocer nuestras raíces intelectuales y por lo tanto a amarlas: de ahí la gran obra editorial sobre el pensamiento ecuatoriano, ya que era simple prejuicio e ignorancia afirmar que nada se había producido fuera de una lírica poco excepcional y de un relato realista y denunciante. La razón atrae; pero la razón sola y seca, terrorífica.

Se le acercaron dos y repitiéronle:

"¡No nos dejes! ¡Valor! ;Vuelve a la vida!"

Pero el cadáver jay.1 siguió muriendo. 
No será palabrería afirmar que si Hernán Malo hubiera sido sólo razón, claro del bosque, punto de orientación, puente de diálogo, no hubieran sentido tanto tantos amigos su muerte y no hubieran dicho: iNo nos dejes' ; Vuelve a la vida! La parte valerosa del alma de Hernán fue muy templada. Intelectualmente se sometió a una duda metódica y descarnada que cuestionó los fundamentos de sus convicciones y existencia. Fue un templo costoso que le hacía temblar en los cimientos y le nublaba el apacible claro del bosque.

Algo de Karamazov había en él que lo exaltaba. Rompió estereotipos ancestrales, hizo la experiencia de lo humano, ecuatorianizó su vida social. Este valor le ganó muchos afectos y le acarreó escandalizadas resistencias. Pero si hubiera sido sólo razón y coraje, la gente le hubiera respetado y admirado solamente.

Acudieron a él veinte, cien, mil, quinientos mil clamando: ";Tanto amor y no poder nada contra la muerte!".

Pero el cadáver ;ay! siguió muriendo.

No será indecoroso afirmar que si tantos al saber de su muerte dijeron con dolor ;Tanto amor y no poder nada contra la muerte! es porque la parte apetitiva de su alma era pura inseguridad interior, compasión por lo humano, instinto certero para desinflar la altanería insatisfecha, soledad sin fondo, largas y clarividentes indecisiones. La gente veía en él, sentía en él, intuía en él un compañero en la misma barca frágil de las frustraciones humanas. Se dio la paradoja de que su debilidad acercó muchos sobresaltos, de que su inseguridad empecinó a muchos corazones a encapricharse, a pesar de todos los pesares, vivir con distinción, con humos y con coraje.

Le rodearon millones de individuos con un ruego común: "iQuédate, hermano!"

Pero el cadáver jayj siguió muriendo.

Entonces todos los hombres de la tierra le rodearon; les vio el cadáver triste emocionado; incorporóse lentamente, abrazó al primer hombre; echóse a andar.... 
No será improbable afirmar que con su muerte la obra de Hernán Malo González se echará a andar. Ha dejado discípulos y amigos, libros escritos, una corporación editora seria que difunde lo nacional y pronto publicará, gracias a lo que supo sembrar: razón, coraje, humanidad, amor a la patria, una monumental Historia del Ecuador no escrita por Malo, pero sí nacida al calor de su abrazo, y un pensamiento claro y avanzado para la universidad ecuatoriana.

No será por lo mismo sin sentido afirmar con su Vallejo amado:

dejásteme

verte desde este lobo, padecer, pelear por todos y pelear

para que el individuo sea un hombre, para que los señores sean hombres, para que todo el mundo sea un hombre, y para que hasta los animales sean hombres, el caballo, un hombre, el reptil, un hombre, el buitre, un hombre honesto, la mosca, un hombre, y el olivo, un hombre y hasta el ribazo, un hombre y el mismo cielo, todo un hombrecito! 
